\title{
El concepto de 'imperio' en el pensamiento político griego clásico ${ }^{1}$
}

\author{
The Concept of 'Empire' \\ in Classical Greek Political Thought
}

\author{
Diego Alexander OliverA \\ https://orcid.org/0000-0002-8167-2161 \\ Universidad Autónoma de Entre Ríos-Consejo Nacional de Investigaciones Científicas y Técnicas, \\ República Argentina \\ diego_alexander_olivera@yahoo.com.ar
}

RESUmen: En este artículo se estudiará el concepto de 'imperio' en el pensamiento político griego clásico. El objetivo es argumentar que el mismo configura una noción de imperio en la que coexisten la idea de una autoridad legítima y otra enfocada en la dominación despótica. Esto es importante porque procura inscribir el concepto dentro de la cosmovisión griega evitando su comparación con la concepción moderna. Finalmente, se afirma que ambas formas de conceptualizar la noción de imperio resultan de la tensión existente en el marco interestatal entre la voluntad igualitaria de la polis y sus objetivos expansionistas.

Palabras clave: Atenas, arché, imperio, krátos

ABSTRACT: In this article we shall study the notion of 'empire' in classical Greek political thought. Our aim is arguing that such a concept establishes a notion of empire in which live together the ideas of legitimate authority and of despotic domination. This is important because we seek to register that notion within the Greek worldview, avoiding comparison with the Modern conception. Finally, we assert that both ways of conceptualizing the notion of empire emerge from the extant tension within the State between the egalitarian volition of the polis and its expansionist targets.

Keywords: Athens, arché, Empire, krátos

ReCibIDO: 05/08/2019 • ACEPTADO: 10/09/2019 • Versión FinAL: 13/12/2019

\footnotetext{
${ }^{1}$ Agradezco al Dr. Álvaro Moreno Leoni la lectura previa y los comentarios realizados a este trabajo. 


\section{INTRODUCCIÓN}

Moses Finley daba inicio a su clásico artículo sobre el imperio ateniense con una sutil crítica a sus contemporáneos, en especial a Édouard Will, por la tendencia a reemplazar el término moderno 'imperio' por el más helénico de 'hegemonía'. ${ }^{2}$ Cuatro décadas después, la crítica finleyana es de una vigencia sorprendente. En efecto, la historiografía actual sobre el imperio ateniense insiste en que el término $\operatorname{arché}^{3}$ es, en la lengua griega clásica, el utilizado para evocar la idea de imperio. ${ }^{4}$ Édouard Will ya había ido en esa dirección en el texto objeto de la crítica de Finley, pero la idea fue esgrimida originalmente por Jacqueline de Romilly en su libro Thucydide et l'impérialisme athénien. ${ }^{5}$

Hoy no existen motivos para seguir sosteniendo la tesis de Romilly pues se han hecho las observaciones pertinentes respecto a que los griegos de la Antigüedad usaban otros vocablos, además de arché, para referirse a la situación ateniense en el Egeo. ${ }^{6}$ Una vez más hay que señalar, como lo hiciera Finley, que reemplazar el término moderno por uno más griego es un camino poco provechoso. ${ }^{7}$

Tal vez la confusión en que se mueve la historiografía contemporánea sobre el imperio ateniense es resultado de dos cuestiones, no necesariamente complementarias, pero que se alimentan una a otra: por un lado, está la preeminencia de una sola fuente que usa arché en sentido de imperio, esto es, Tucídides. Por otro, hay una vacancia historiográfica en torno al concepto de imperio y lo que el pensamiento político griego clásico entiende como tal. ${ }^{8}$ En este artículo se pretende estudiar este último punto, proponiendo

${ }^{2}$ Finley 2000, p. 61, y Will 1997, pp. 157-158.

${ }^{3}$ En adelante los términos en griego serán transliterados según lo acostumbrado en el área disciplinar en que se inscribe este trabajo que es el de la Historia de las Ideas Políticas.

${ }^{4}$ Cf. Samons 2010, p. 13; Kallet 2002, p. 197, y Pérez Martínez 2014, pp. 121-145.

${ }^{5}$ De Romilly 1947, p. 19.

${ }^{6}$ Champion 2009, p. 87, señala los términos krátos y dynasteía. Loraux 2007, p. 253, indica el uso de la voz krátos para referirse al dominio de Atenas sobre sus aliados, y arché para hablar de las relaciones de gobierno al interior de la ciudad. Sin embargo, Gallego 2011, pp. 155-166, y Olivera 2015, pp. 11-29, apuntan a una utilización indistinta de ambas palabras para describir situaciones de dominio tanto hacia el exterior como al interior. Por su parte, Samons 2010, p. 13, y Kyrtatas 2002, p. 152, observan un empleo metafórico del término douloun para evocar la idea de dominación entre ciudades a partir del modelo ofrecido por la esclavitud.

${ }^{7}$ El debate entre Finley y Will se inscribe en una polémica mayor sobre la pertinencia o no de usar conceptos modernos, como 'imperio' o 'imperialismo', para realidades que desconocen dichos vocablos.

${ }^{8}$ Morris 2009, p. 128, señala que, a pesar de que existe un cuidadoso análisis filológico del griego de Tucídides que lleva a traducir arché como imperio, los historiadores modernos no se preocupan mucho por especificar qué significa 'imperio' en inglés o cualquier otra lengua moderna. 
algunas directrices para formular un concepto de imperio conforme a lo que el vocabulario utilizado por las fuentes nos permite inferir. En esta línea, se analiza el empleo de varios términos que en diversos contextos discursivos expresan y representan una lógica de dominación imperial. Dichos vocablos son arché, junto con krátos, douleía y hegemonía.

Por una parte, si bien el problema es general, y tiene que ver con asir la noción de imperio en el pensamiento político clásico a los fines pragmáticos, aquí se van a discutir los problemas semánticos, teóricos y prácticos en la etapa clásica. Por otra, como punto de partida, se considera que la irrupción del imperialismo persa y la conformación de un dominio naval ateniense en el Egeo configuraron una situación novedosa en relación con el ejercicio del poder en el marco de las relaciones inter-póleis. ${ }^{9}$ Por tanto, la pluralidad terminológica no puede escindirse de cierta voluntad de ensayar respuestas a la irrupción del fenómeno imperial y de dotarlo de inteligibilidad. En esta tesitura, la variedad no evidencia tanto una ausencia conceptual sino una interrelación de ideas e imágenes que buscan dar cuenta de la realidad imperial. Así pues, el léxico del poder resulta una puerta de entrada más que justificable para desentrañar aspectos del pensamiento político en relación con el imperio. ${ }^{10}$ Por último, aunque se contemplan diversas fuentes, este trabajo se centra en tres de ellas: Heródoto, Tucídides y Aristóteles (Política). Otros términos, como dýnamis o dynasteía, serán analizados en una instancia posterior.

\section{IMPERIO COMO ARCHÉ}

En el griego de Tucídides arché es el término con el que comúnmente se denomina al imperio ateniense. ${ }^{11}$ En su obra hay una clara distinción entre arché y hegemonía. Esta última constituye una forma más flexible de alianza y se usa básicamente para referirse a la coalición del 478 a. C. que dio lugar a la creación de la Liga de Delos. ${ }^{12}$ Por el contrario, a la fisonomía que adopta la Liga en el 431 a. C., al comenzar la guerra contra Esparta, se le llama arché, afirmando que estaba basada en el poder. ${ }^{13}$

Sin embargo, urge realizar dos precisiones acerca de esto. En primer lugar, a pesar de su centralidad, arché no es el único vocablo que Tucídides

\footnotetext{
${ }^{9}$ Raaflaub 1994, pp. 114-118, y Balot 2009, p. 55.

${ }^{10}$ Sin perder de vista los procesos de conformación de la pólis griega que venían desarrollándose con anterioridad y que fueron afectados por la irrupción del imperio. Cf. Morris 2009, p. 103.

${ }^{11}$ Ejemplo, Th., 2, 63, ed. 1942: toû árchein. 1, 93, 4, y 3, 37, 2: tèn archén.

12 Th., 1, 97, ed. 1942.

13 Th., 1, 99, ed. 1942.
} 
utiliza para referirse al poder imperial. ${ }^{14}$ Segundo, ya en Heródoto tenemos un uso en la misma dirección y una diferencia respecto a hegemonía. ${ }^{15}$ En efecto, según ha demostrado Pascal Payen, en el historiador de Halicarnaso la hegemonía da cuenta de una situación determinada por el instante posterior a la conquista o victoria militar. ${ }^{16}$ Está ligada al acontecimiento que le precede, esto es, a la guerra o batalla que instaura un vencedor, quien por un lapso de tiempo se erige como hegemón en la arena internacional. La eficacia en el ejercicio del poder interestatal permite que la hegemonía se convierta en un poder que se extiende sobre un registro temporal más amplio, deviene pues en arché. Payen lo sintetiza de la siguiente manera al afirmar que en Heródoto "la arché es una dominación que se inscribe en el tiempo [...] porque significa una supremacía destinada a durar". ${ }^{17}$

Ahora bien, en el mismo Heródoto, como en otros autores antiguos, hay también un empleo claro de arché en relación con el ejercicio de las magistraturas cívicas y con el gobierno al interior de la ciudad. ${ }^{18}$ En Aristóteles, como ha hecho notar Claude Mossé, el vocablo se utiliza en particular para las funciones con tiempo limitado ya sea por sorteo o elección. ${ }^{19}$ En otras palabras, dicho vocablo implica claramente la idea de 'magistraturas' cívicas. De hecho, la voz arché tiene el sentido de 'comienzo', 'origen' o 'principio', y ése es el uso que le da la mayoría de los filósofos. Rubén Dri señala que para Aristóteles la filosofía es la ciencia de los primeros principios, como los primeros principios mandan, de ahí que arché pueda significar poder. ${ }^{20}$ Es posible que una tradición aristocrática, de la que el Estagirita se hace eco,

14 Th., 1, 143, 5, ed. 1942: krátos. 2, 43, 1: tèn tes póleos dýnamin. También 1, 18, 1-2, para referirse a la situación espartana en el Peloponeso, dynámenoi, dynámei. 1, 96, 1: hegemonía.

15 Arché en Heródoto, cf. Hdt., 1, 53, 3, ed. 1920: megálen archén. 7, 168, 2, ed. 1938: pollón árchein.

16 Payen 1997, pp. 193-203.

17 Payen 1997, p. 194.

18 Ejemplo, Hdt., 3, 80, 6, ed. 1928 y trad. de Schrader: "Una multitud que gobierna (plêthos árkhon) [...] desempeña los cargos (arkhàs árkhei) por sorteo y ejerce un poder (arkhén) sometido a rendición de cuentas [...]". También X., Const. Ath., 1, 3, ed. 1969 y trad. de Guntiñas Tuñon: "pues el demos (ho dêmos) comprende que se beneficia más al no ejercer estos cargos (árkhein taútas tàs arkhás) él mismo, sino al dejar a los más poderosos ejercerlos (árkhein). Pero cuantos cargos (arkhaí) sirven para la mistoforía y el beneficio del hogar, el pueblo busca ejercerlos (ho dêmos árkhein)". En Arist., Ath., 3, 1-4, ed. 1920 y trad. de García Valdés: "El ordenamiento del régimen primero (arkhaías politeías), el anterior a Dracón, era el siguiente: designaban los cargos (arkhàs) en razón del rango y de la riqueza y los ejercían, a lo primero, de por vida, luego, por un decenio. Los cargos (árkhon) más importantes y los primeros fueron rey, comandante en jefe y arconte (Basileús kaì polémarkhos kaì árkhon) [...] Los legisladores (thesmothétai) comenzaron a elegirse muchos años después, cuando los cargos (arkhàs) eran ya elegidos cada año, con el fin de que custodiaran los preceptos, tras haberlos puesto por escrito, para la resolución de cuestiones litigiosas".

${ }^{19}$ Mossé 1979, p. 242.

${ }^{20}$ Dri 1999 , p. 73. 
reconocía como principio de toda autoridad a las magistraturas. Por tanto, ese término suele utilizarse con la idea de 'comienzo', 'magistratura' y 'poder'.

Así pues, cuando Aristóteles emplea arché con sentido de imperio no debe omitirse lo que el término implica para él. En otras palabras, cuando en la Política señala que el rey de Persia subyugó a babilonios y muchos otros pueblos "orgullosos por haber tenido en otro tiempo el imperio (árches)", no hace más que una elección que es acorde con el uso que le da a dicho término en la mayor parte de su obra. ${ }^{21} \mathrm{Si}$ el Estagirita ha considerado la voz arché como la apropiada para hablar de las magistraturas y del gobierno al interior de la ciudad, es coherente que defina a la autoridad persa (o de cualquier otra monarquía bárbara) como un árchein. En efecto, para él la monarquía es un tipo de régimen y la realeza (basileía) es una magistratura que, en condiciones como la de los pueblos bárbaros, se destaca por su despotismo. La autoridad del monarca sobre el espacio que constituye el Estado persa es total y absoluta. Por ende, es factible que se confunda esa autoridad con el territorio, en tanto que la arché del Gran Rey se despliega sobre la totalidad del espacio que conquistaron los persas.

En todo caso, queda claro que en las fuentes no hay un empleo indiscutible del término con significado de imperio; por el contrario, hay otros usos relacionados con el gobierno de la ciudad, los cargos públicos y el origen mismo del poder.

\section{IMPERIO COMO KRÁTOS}

A diferencia del historiador de la guerra del Peloponeso, la epigrafía ateniense utiliza el verbo krateîn y sus derivados para referirse al vínculo que une a la ciudad con sus aliados. ${ }^{22}$ Ya en Homero el término krátos supone una 'superioridad' o 'prevalencia' de carácter física o moral que se obtiene en la asamblea o en el combate. De ahí su sentido de 'poder' como dominio propio o 'potencia' territorial y política. En su variante krateîn llega a significar 'gobernar' o 'tener la autoridad'.23 Pero se trata de una autoridad lograda con el ejercicio de la 'fuerza', por lo que a veces suele traducirse como tal. ${ }^{24}$ En la tradición mítica se

\footnotetext{
${ }^{21}$ Arist., Pol., 1284a 19, ed. 1957.

${ }^{22}$ Una de las expresiones que aparece en mayor cantidad de casos es póleis hosón Athenaîoi kratoûsin. Cf. Low 2005, pp. 95-100.

${ }^{23} \mathrm{El}$ verbo krateîn, que aparece en Hom., Il., 1, 79, o en 1, 288, por ejemplo, tiene una clara connotación de ejercicio de un dominio o gobierno. Cf. Benveniste 1983, p. 285.

${ }^{24}$ Gallego 2003, p. 189, sostiene que krátos "señala la presencia de una fuerza más que la de un gobierno". Sin embargo, en Homero existen otros términos que pueden traducirse como 'fuerza': bía, ís, iskhús, sthénos, alké, dýnamis.
} 
asocia a bía (violencia) en tanto que ambos son hijos de la oceánide Estigia y acólitos de Zeus. En la tragedia de Esquilo son precisamente Krátos y Bía quienes encadenan a Prometeo por orden del Dios. Representan la personificación del poder absoluto, irresistible e irracional de Zeus. ${ }^{25}$

En época clásica el vocablo mantuvo su significación homérica en lo que respecta a las relaciones entre póleis. Su centralidad es tal en ese aspecto que constituye la verdadera "loi de la guerre". ${ }^{26}$ En Heródoto el término se vincula a los procesos de conquista y a las circunstancias propias de la lucha en que un sector logra la superioridad sobre otro. ${ }^{27}$ Es a partir de esa victoria que el vencedor puede desplegar una hegemonía. Esto sugiere que el tipo de poder logrado a partir de tal superioridad es limitado en el tiempo. Aquí radica la diferencia entre el uso que la tradición hace del término con el empleado por la epigrafía, pues en tales documentos krátos parece significar mucho más, no se refiere sólo a una victoria militar o a una conquista, sino que "el poder de Atenas, la frase sugiere, es algo casi visible, tangible; ciertamente algo que suplanta cualquier otro tipo de krátos militar o político que puedan existir dentro o entre estas póleis". ${ }^{28} \mathrm{O}$ lo que es lo mismo, un poder destinado a perdurar en el tiempo.

En Tucídides, en cambio, hay una utilización que en mayor medida relaciona a krátos con el gobierno del dêmos y con la posibilidad del mismo de derivar en stásis. ${ }^{29}$ Ya en Heródoto hay un empleo en esa misma dirección. ${ }^{30}$ Luego, en Platón, el carácter del gobierno popular, un krateîn, señalará su condición anárquica. ${ }^{31}$ Esos usos en clave de gobierno al interior de la polis desarticulan la idea de que los atenienses olvidaron o negaron el krátos en la política doméstica. ${ }^{32}$ Por lo menos no fue así en el siglo $\mathrm{v}$ a. C. ${ }^{33}$

Por último, Aristóteles, en la misma cita en que utiliza arché para referirse al imperio persa, describe la posición ateniense en el Egeo con el término énkratos, literalmente 'estar en posición del poder', que suele traducirse como 'dominio'. ${ }^{34}$ Pero allí también generaliza con la palabra dynámeos el ejercicio del poder a escala interestatal. Por tanto, en lo que concierne a política exterior, el vocabulario del Estagirita es bastante laxo en materia terminológica.

25 Vernant 1992, p. 68.

${ }^{26}$ Payen 2012, p. 96.

${ }^{27}$ Hdt., 3, 117, ed. 1928: tò perseôn krátos. 7, 168, ed. 1938: katakratésanta. Cf. Payen 1997, pp. 193-196.

${ }^{28}$ Low 2005, p. 96.

${ }^{29}$ Ober 1998, pp. 66-67. Th., 4, 98, 2, ed. 1942, 8, 46, 1, y 8, 76, 4.

${ }^{30}$ Hdt., 3, 81, 1, ed. 1928: plêthos tò krátos.

${ }^{31}$ Rancière 1996, pp. 83-99, y Gallego 2018, pp. 27-28.

${ }^{32}$ Loraux 2008b, pp. 251-272.

${ }^{33}$ Gallego 2011 y Olivera 2015.

${ }^{34}$ Arist., Pol., 1284a 19, ed. 1957. 
En conclusión, aunque krátos tiene un nexo con los procesos de conquistas y las instancias de victoria en el plano militar, no hay un empleo homogéneo del término. A veces se usa para enunciar una dominación imperial, otras, lo hace sólo en relación con el momento en que la supremacía se ha logrado. Un empleo similar se da al interior de la ciudad, donde puede evocar la circunstancia propia de la lucha facciosa en que el dêmos obtiene la victoria sobre la aristocracia, o bien, alude al gobierno instituido y organizado a partir de la supremacía popular.

\section{IMPERIO COMO HEGEMONÍA}

En términos de relaciones interestatales la noción de hegemonía, tal como la conciben los griegos, implica una superioridad ejercida sobre iguales. ${ }^{35}$ Tiene un largo vínculo con la idea de 'mando' o 'jefatura' de tipo militar. El hegemón era aquel que guiaba o dirigía, el 'general' o 'caudillo'. Dicha palabra está asociada al concepto de justicia (díke), tanto porque el ejercicio de la hegemonía sea justo por haberlo ganado, como porque no presupone un derecho de injerencia en los asuntos internos de las demás ciudades. ${ }^{36}$ Ello significa que el ejercicio de la hegemonía no implicaba necesariamente abolir la autonomía de las ciudades subordinadas. No sólo se respetaba el autogobierno, también se daba a los aliados ciertas libertades en política exterior sobre las que se afirmaban las pretensiones de ser "independiente". ${ }^{37}$

Además, las ciudades hegemónicas necesitaban generar consensos en determinadas áreas de interacción y las subordinadas podían sacar provecho del grado de competencia entre las póleis hegemónicas de Atenas, Esparta y Tebas. Según Tucídides, parte del argumento del demagogo Cleón para conseguir que la asamblea votara a favor de la destrucción de la pólis de Mitilene, que intentó salirse de la alianza en 427 a. C., fue que los mitileneos eran unos desagradecidos porque Atenas a ninguna otra ciudad aliada respetó tanto su autonomía. ${ }^{38}$ En otras palabras, a diferencia de otras

${ }^{35}$ Loraux 2012, p. 109.

36 Antela-Bernárdez 2007, p. 74.

${ }^{37}$ Para el pensamiento político griego la noción de soberanía de una pólis no excluía la dependencia. Por tanto, una ciudad podía ser autónoma sin ser necesariamente independiente en el sentido moderno del término. Cf. Grandjean \& Hoffmann 2012, p. 71, y López Barja 2012, pp. 85-88. Hansen 2006, pp. 48-50, considera que la voz autonomía significaba 'independencia' con anterioridad a la batalla de Queronea, luego sólo tenía el sentido de 'autogobierno'.

38 Th., 3, 39, trad. de Torres Esbarranch: "pero cuando han cometido una tal acción los habitantes de una isla provista de fortificaciones, que solo podían temer a nuestros enemigos por mar - en un campo en que tampoco estaban sin defensa gracias a su escuadra de trirremes - y que vivían autónomos y eran respetados por nosotros al máximo, ¿qué otra cosa han hecho estas gentes sino urdir una agresión y promover la subversión más que lanzarse a una rebelión (la 
póleis, Mitilene gozaba de un estatus de igual a Atenas y no de subordinada. ${ }^{39}$

Ahora bien, resulta pertinente detenerse en dos términos que se asocian con la hegemonía en el ejercicio del poder a escala interestatal; éstos son eunóia y cháris. El campo semántico de ambos vocablos es similar. Cháris implica la idea de 'benevolencia' en el sentido de 'otorgar un favor', ser 'indulgente', conceder un 'servicio' o 'beneficio'. En tanto eunóia significa 'benevolencia' con el sentido de 'buena disposición', o bien, 'buena voluntad', 'confianza', 'adhesión'. ${ }^{40}$ Las dos palabras se vinculan con una concepción de justicia, reciprocidad y voluntariedad que está en la base de la noción de hegemonía. ${ }^{41}$

En cuanto a la cháris eso es evidente cuando Pericles en el Discurso fúnebre, trasmitido por Tucídides, afirma que la ciudad hace amigos "otorgando favores", no pidiéndolos. ${ }^{42}$ Se trata de una clara referencia al papel de la ciudad como salvadora de Grecia en las Guerras Médicas que legitima el lugar ocupado por Atenas en la alianza. ${ }^{43} \mathrm{El}$ otorgamiento de favores crea deudores que se ven obligados a mostrar agradecimiento para con la ciudad dominante. La cháris implica tanto la benevolencia de Atenas como la gratitud de los aliados.

Por su parte, la eunóia desempeñaba un rol trascendente en el diálogo hegemonía-autonomía que se daba en las relaciones entre póleis. La ciudad que ostentaba la hegemonía podía alegar tal posición no desde la utilización de la fuerza, sino desde la buena voluntad con que actuaba a favor de sus aliados. De igual forma, las ciudades más débiles, obligadas a aceptar la hegemonía, solían legitimar su posición y le daban coherencia con su aspiración autonómica, a partir de la idea de que el poder que gozaba la polis hegemónica no había sido impuesto sino ganado. Las póleis más débiles entendían la hegemonía como resultado de una adhesión o confianza que ellas depositaban en el liderazgo positivo de la ciudad más poderosa. En el caso ateniense esa confianza estaba en relación, al igual que sucede con la noción de cháris, con el desempeño de la ciudad en la guerra contra el persa.

De esa manera los conceptos de eunóia y cháris permitían vehiculizar un discurso conciliador entre la hegemonía ateniense y la pretensión de autonomía por parte de los aliados. Por tanto, no debe tomarse a la ligera la

rebelión, ciertamente, es propia de quienes han sufrido alguna violencia), y tratar de destruirnos poniéndose al lado de nuestros enemigos más acérrimos?"

${ }^{39}$ Hegemonía significa ‘imperio’ en Th., I, 96, 1, ed. 1942, y en Hdt., 1, 7, ed. 1920.

40 Para cháris, cf. Plácido 1997, p. 39; y para eunóia, cf. Moreno Leoni 2017, pp. 147-151.

${ }^{41}$ Es la idea de Diódoto en Th., 3, 42-48, en que la adhesión de los sectores demócratas de las ciudades aliadas haría justa la hegemonía ateniense.

${ }^{42}$ Th., 2, 40, 4-5, ed. 1942.

${ }^{43}$ Cf. Canfora 2014, pp. 24-37. 
observación hecha por Aristóteles respecto a los motivos por los cuales ir a la guerra. ${ }^{44}$ Allí señala que la hegemonía debe buscarse sólo cuando responde al interés de los aliados. Afirmación coherente con su idea de que un régimen justo busca el interés del todo y no de la parte. ${ }^{45}$ Por eso, los casos históricos de Atenas y Esparta proporcionan para él ejemplos negativos del ejercicio de la hegemonía. ${ }^{46} \mathrm{Al}$ discriminar entre el ejercicio de la hegemonía con la dominación despótica, el Estagirita señala que el control imperial puede estar reglado por un marco normativo de carácter consuetudinario. ${ }^{47}$

Es decir, hegemonía evoca una noción de imperio en que el ejercicio del poder, aunque sustentado en la fuerza, contiene altos niveles de consenso. Implica un ordenamiento de las relaciones entre ciudades donde la dominación aparece desdibujada al confundirse con un reconocimiento que los aliados le otorgan a la metrópolis.

\section{IMPERIO COMO DOULEÍA}

En primera instancia puede resultar desconcertante acercarse al concepto de imperio desde un término que se refiere a otra cosa, para ser más específico, a la idea de esclavitud. En efecto, aunque el vocabulario griego reconoce varias palabras para aludir a un esclavo, doúlos es la más recurrente y la que dio lugar al sustantivo abstracto que enuncia la noción general de esclavitud: douleía ${ }^{48}$ Sin embargo, como ha notado Dimitris Kyrtatas: "las relaciones entre ciudades en tales casos era percibida a la luz de la metáfora del amo y el esclavo". ${ }^{49}$ Por ello es importante ver qué se puede inferir de ese uso en términos de conceptualización.

En esa dirección, se observa una asimilación entre conquista y esclavización. En Heródoto dicha asimilación viene acompañada por la cons-

\footnotetext{
${ }^{44}$ Arist., Pol., 1333b-1334a, ed. 1957 y trad. de García Valdés: "La práctica de los ejercicios militares no debe hacerse por esto, para someter a esclavitud a pueblos que no lo merecen, sino, primero, para evitar ellos mismos ser esclavos de otros, luego para buscar la hegemonía (hegemonían) en interés de los gobernados (archoménon), y no por dominar a todos; y en tercer lugar, para gobernar despóticamente a los que merecen ser esclavos".

45 Arist., Pol., 1279a 11, ed. 1957. Cf. el análisis que dedica al pasaje anterior Buis 2015a, pp. 144-145, donde afirma que "el discurso aristotélico no apunta al interés exclusivo de la autoridad de perpetuarse frente a los súbditos, sino que la hegemonía es entendida en términos de la consagración del bien común”.

46 Arist., Pol., 1296a 18, ed. 1957.

${ }^{47}$ Sobre el carácter consuetudinario del derecho internacional griego, cf. Low 2007; Giovannini 2007, y Buis 2015a.

${ }^{48}$ Chantraine 1999, p. 294, y Paiaro 2012, p. 159.

${ }^{49}$ Kyrtatas 2002, p. 152.
} 
trucción de la figura del Gran Rey persa como déspota. ${ }^{50}$ Eso implica que, como acción despótica, la conquista resulta ser un acto de esclavización. ${ }^{51}$ Un elemento clave en este aspecto es el pago de tributos. Cuando Heródoto describe el sometimiento al mismo, de parte de los territorios conquistados en Grecia por Jerjes, califica esa acción como "sojuzgamiento". 52 Se trata de una descripción que apela a una imagen importada del universo de las relaciones de explotación laboral. Aquí ya no son las categorías políticas de la ciudad las que se utilizan para hacer inteligible la novedad del poder imperial. En su lugar se opta por representar el fenómeno desde prácticas vinculadas con la vida privada, al oíkos.

Para el historiador de la guerra del Peloponeso, la conquista de Esciros (469 a. C.) es una reducción a la esclavitud y la de Naxos un sometimiento. ${ }^{53}$ No se detiene allí. Tucídides hace un uso inequívoco del término doúlos como sinónimo de conquista que termina por asimilar aliados con esclavos. ${ }^{54}$ Esa asimilación no es azarosa. En el fondo se trata de describir las asimetrías entre Atenas y sus aliados. Los griegos entendían el ejercicio del poder entre amo y esclavo como una dominación despótica, y la metáfora esclavista contribuía a representar el imperio como un ejercicio análogo. La idea de 'dominación' incluye todo tipo de relaciones de dependencia, incluso aquellas que requieren ciertos niveles de 'explotación' o que, desde la perspectiva moderna, suponen un derecho de propiedad..$^{55}$

El léxico de Aristóteles va un poco más allá y asocia esclavización con un cambio de estatus en la situación de los aliados. En el pasaje antes mencionado, sobre los motivos por los cuales ir a la guerra, señala que debe hacerse para evitar ser 'esclavos' y para 'esclavizar' a quienes merecen ser esclavos. ${ }^{56}$ Cuando la hegemonía ateniense deja de significar un gobierno que contempla los intereses de los gobernados se convierte en dominación despótica que trata a los aliados como esclavos. En esa coyuntura, los aliados (sýmmachoi), en especial quienes pagan el tributo, devienen en súbditos (hypékooi). Ese desplazamiento marca para el Estagirita la conversión de la alianza en un imperio..$^{57}$

${ }^{50}$ Sobre esa imagen, cf. Hartog 2003.

${ }^{51}$ Plácido 1986, p. 24.

52 Hdt., 7, 108, 1, ed. 1938: ededoúloto.

53 Th., 1, 98, 1-4, ed. 1942. Esciros; endrapódisan derivado del vocablo andrápodon que se refiere a quien ha sido capturado en una guerra y convertido en esclavo. Cf. Buis 2015a, p. 194, Naxos; edoulóthe.

${ }^{54}$ Th., 1, 69, 1, ed. 1942: dedouloménous, doulosámenos. 3, 10, 4: symmáchon doúlosin. 3 , 10, 5: edoulóthesan. 7, 66, 2: katadoulósei.

${ }^{55}$ Kyrtatas 2002, Vlassopoulos 2011, Paiaro 2012.

56 Arist., Pol., 1333b-1334a, ed. 1957: douleýsosin, douleýein.

57 Arist., Pol., 1333b 19, trad. de García Valdés: "No tienen una concepción correcta del poder que el legislador debe manifiestamente honrar, pues el gobierno de hombres libres es más 
Así pues, la sociedad imperio/esclavitud configura una noción de imperio cercana a las prácticas que en Aristóteles se definen como pre-políticas; esto es la casa y la aldea. ${ }^{58}$ Es decir, no evoca la idea de un ordenamiento institucional regulado por normas, sino la simple dominación por un uso reiterado de la fuerza militar. En este sentido, el imperio resulta de una victoria (krátos) que al esclavizar borra cualquier pretensión autonómica de parte de los aliados.

\section{CONCLuSIÓN}

En el marco de las relaciones interestatales, en el mundo griego existía una tensión entre una voluntad igualitaria (a modo de proyección de los valores propios de la pólis, en especial, la isonomía) y los objetivos expansionistas. ${ }^{59}$ Esa tensión se evidencia en los términos analizados que dan cuenta de una pluralidad de formas en que el pensamiento político griego aprehendió el fenómeno imperial. En ocasiones, la voluntad isonómica permitía pensar el imperio como una dominación instituida y regulada por normas e instituciones. En otras, en cambio, la vocación expansionista, en ansias de encontrar justificación, trasmite una imagen del imperio como gobierno del más fuerte.

Así pues, no parece posible sintetizar conceptualmente lo que el pensamiento político griego entendía por imperio. Sin embargo, es factible, a grandes rasgos, señalar dos nociones, que en las fuentes estudiadas se encuentran yuxtapuestas, y que pueden servir de aproximación a un concepto de imperio:

- Imperio es autoridad legítima instituida y regulada por instancias jurídicas y una vocación panhelénica, en la cual se articulan la pretensión autonomista de las póleis y la realidad de un marco interestatal inestable en que más de una vez la fuerza actúa como eje ordenador.

- Imperio es una dominación despótica en la que una pólis ejerce una superioridad militar y política sobre otras. Esto es, la capacidad de anular la autonomía de los aliados y de explotarlos económicamente en favor de la ciudad imperial.

En ambos casos el factor temporal es importante. El imperio se diferencia de cualquier otra forma de ejercicio del poder porque se inscribe en un

noble y más conforme a la virtud que el gobierno despótico. Tampoco por esto debe considerarse feliz la ciudad ni loable al legislador por ejercitar a los ciudadanos a vencer para dominar a sus vecinos, ya que esto conlleva un gran daño".

${ }^{58}$ Arist., Pol., 1252b 6, ed. 1957. Cf. Olivera 2018.

${ }^{59}$ Buis 2015b, pp. 27-61. 
marco temporal amplio, es capaz de perdurar. Ciertas prácticas constitutivas de la pólis - como la alternancia, el sorteo o la elección, que marcan el carácter transitorio del ejercicio del poder- están ausentes. Asimismo, en términos de conflictos interestatales, desde la etapa arcaica el rasgo agonal de los mismos hacía que la lucha fuera por la supremacía y no tanto con pretensión de conquista. ${ }^{60}$ Por tanto, el desenlace de los conflictos no daba lugar a un control sobre los vencidos que se prolongara más allá de las circunstancias propias del momento.

Así pues, retomando el debate con que iniciamos, es oportuno hacer dos menciones al respecto a modo de conclusión. En primer lugar, si bien la corriente filológica iniciada por Jacqueline de Romilly supuso un avance importante en la comprensión del léxico griego del poder, generalizar a partir del caso de Tucídides no parece un camino de provecho. Menos provechoso resulta omitir el término moderno de imperio en favor de palabras griegas. Segundo, el uso del concepto de imperio para el caso de la Grecia clásica debe tener cierta precaución. Un acercamiento que Christophe Pébarthe, siguiendo a Nicole Loraux, define como un abordaje desde un uso moderado del anacronismo. ${ }^{61}$

\section{BIBLIOGRAFÍA}

\section{Fuentes antiguas}

Aristóteles, Constitución de los atenienses, trad. Manuela García Valdés, Madrid, Gredos, 1984.

Aristóteles, Política, trad. Manuela García Valdés, Madrid, Gredos, 1988.

Aristotle, Athenaion Politeia, ed. Frederic George Kenyon, Oxford, Clarendon Press, 1920.

Aristotle, Politics, ed. William David Ross, Oxford, Clarendon Press, 1957.

Heródoto, Historia. Libros III-IV, trad. Carlos Schrader, Madrid, Gredos, 1995.

Herodotus, The Persian Wars. Books I, transl. Alfred Denis Godley, Cambridge, Harvard University Press, 1920.

Herodotus, The Persian Wars. Books III-IV, transl. Alfred Denis Godley, LondonNew York, William Heinemann (Loeb Classical Library), 1928.

Herodotus, The Persian Wars. Books V-VII, transl. Alfred Denis Godley, LondonNew York, William Heinemann (Loeb Classical Library), 1938.

\footnotetext{
${ }^{60}$ Sobre el carácter agonal de la guerra, cf. Détienne 1999, p. 163, y Buis 2015a, pp. 158163. Para la inferioridad de los intereses materiales respecto al honor en la guerra arcaica y comienzos de la etapa clásica, cf. Van Wees 2002, p. 98. De hecho, es posible que sea precisamente la experiencia imperial ateniense la que terminó por darle a los intereses económicos un lugar relevante, junto al honor, entre los objetivos de la guerra, al respecto cf. Van Wees 2004, pp. 31-32.

${ }^{61}$ Pébarthe 2011,pp. 57-88, y Loraux 2008a, pp. 201-217.
} 
Homero, Ilíada, trad. Emilio Crespo Güemes, Madrid, Gredos, 1996.

Pseudo Jenofonte, La República de los atenienses, trad. y notas Orlando Guntiñas Tuñon, Madrid. Gredos, 1984.

Thucydides, Historiae, ed. Henry Stuart Jones \& Johannes Enoch Powell, Oxford, Oxford University Press, 1942.

Tucídides, Historia de la Guerra del Peloponeso, intr., trad. y notas Juan José Torres Esbarranch, Madrid, Gredos, 1992.

Xenophontis Opera omnia, vol. 5, ed. Edgar Cardew Marchant, Oxford, Clarendon Press, 1969.

\section{Fuentes modernas}

Antela-Bernárdez, Borja, "Hegemonía y panhelenismo: conceptos políticos en tiempos de Filipo y Alejandro", Dialogues d'histoire ancienne, 33/2, 2007, pp. 69-89, DOI: 10.3406/dha.2007.3041.

BALOT, Ryan K., "The Freedom to Rule: Athenian Imperialism and Democratic Masculinity", in David Edward Tabachnick \& Toivo Koivukoski (eds.), Enduring Empire: Ancient Lessons for Global Politics, Toronto, University of Toronto Press, 2009, pp. 54-68.

Benveniste, Émile, Vocabulario de las instituciones indoeuropeas, Madrid, Taurus, 1983.

Buss, Emiliano, La súplica de Eris. Derecho internacional, discurso normativo y restricciones de la guerra en la antigua Grecia, Buenos Aires, Eudeba, 2015a.

Buss, Emiliano, "Between Isonomía and Hegemonía: Political Complexities of Transitional Justice in Ancient Greece", in Morten Bergsmo, Cheah Wui Ling, Tianying Song \& Yi Ping (eds.), Historical Origins of International Criminal Law: Volume 3, Brussels, Torkel Opsahl Academic EPublisher, 2015b, pp. 27-61, www.toaep.org/ps-pdf/22-bergsmo-cheah-song-yi (02/05/2016).

CAnfora, Luciano, El Mundo de Atenas, Barcelona, Anagrama, 2014.

Champion, Craig, "Imperial ideologies, Citizenship Myths, and Legal Disputes in Classical Athens and Republican Rome", in Ryan K. Balot (ed.), A Companion to Greek and Roman Political Thought, London, Blackwell, 2009, pp. 85-99.

Chantraine, Pierre, Dictionnaire étymologique de la langue grecque. Histoire des mots, Paris, Klincksieck, 1999.

De Romilly, Jacqueline, Thucydide et l'impérialisme athénien: la pensée de l'historien et la genèse de l'œuvre, Paris, Les Belles Lettres, 1947.

DÉTIENNE, Marcel, "La phalange: problèmes et controverses", en Jean-Pierre Vernant (éd.), Problèmes de la guerre en Grèce ancienne, Paris, Le Seuil, 1999.

Dri, Rubén, "Filosofía política aristotélica", en Atilio A. Boron (comp.), La filosofía política clásica. De la Antigüedad al Renacimiento, Buenos Aires, Consejo Latinoamericano de Ciencias Sociales, 1999, pp. 58-85, http://bibliotecavirtual. clacso.org.ar/clacso/se/20100609122906/4dri.pdf (10/10/2015).

Finley, Moses, La Grecia antigua, Barcelona, Crítica, 2000.

GAllego, Julián, La democracia en tiempos de tragedia: asamblea ateniense y subjetividad política, Buenos Aires, Miño y Dávila, 2003. 
Gallego, Julián, “Atenas, entre el Krátos y la Arkhé: el lenguaje de la hegemonía y el agotamiento de la democracia", en Juan Manuel Cortés Copete, Elena Muñiz Grijalvo \& Rocío Gordilla Hervás (coords.), Grecia ante los Imperios: $V$ Reunión de historiadores del mundo griego, Sevilla, Universidad de Sevilla, 2011, pp. 155-166.

GAllego, Julián, La anarquía de la democracia. Asamblea ateniense y subjetivación del pueblo, Buenos Aires, Miño y Dávila, 2018.

Giovannini, Adalberto, Les relations entre États dans la Grèce antique. Du temps d'Homère à l'intervention romaine (ca. 700-200 av. J.-C.), Stuttgart, Franz Steiner Verlag (Historia Einzelschriften, 193), 2007.

Grandjean, Catherine, Geneviève Hoffmann, Laurent Capdetrey \& Jean-Yves CarrezMaratray, Le Monde Hellénistique, Paris, Armand Colin, 2012.

Hansen, Mogens, Polis. An Introduction to the Ancient Greek City-State, Oxford, Oxford University Press, 2006.

Hartog, François, El espejo de Heródoto. Ensayo sobre la representación del otro, Buenos Aires, Fondo de Cultura Económica, 2003.

KALlet, Lisa, "El siglo v: narraciones políticas y militares", en Robin Osborne (comp.), La Grecia Clásica, Barcelona, Crítica, 2002, pp. 191-219.

Kyrtatas, Dimitris J., "Domination and Exploitation", in Paul Cartledge, Edward E. Cohen \& Lin Foxhall (eds.), Money, Labour and Land. Approaches to the economics of Ancient Greece, London-New York, Routledge, 2002, pp. 140-155.

LóPEz BARJA, Pedro, "La ciudad antigua no era un Estado", en Eleonora Dell'Elicine, Héctor Francisco, Paola Miceli y Alejandro Morin (coords.), Pensar el Estado en las sociedades precapitalistas. Pertinencias, límites y condiciones del concepto de Estado, Buenos Aires, Universidad Nacional de General Sarmiento, 2012, pp. 79-92, https://ediciones.ungs.edu.ar/wp-content/uploads/.../9789876301374completo.pdf (20/02/2017).

Loraux, Nicole, "Notas sobre el uno, el dos y lo múltiple", en Miguel Abensour (comp.), El espíritu de las leyes salvajes: Pierre Clastres o una nueva antropología política, Buenos Aires, Ediciones del Sol, 2007, pp. 243-260.

LoRAux, Nicole, La guerra civil en Atenas. La política entre la sombra y la utopía, Madrid, Akal, 2008a.

Loraux, Nicole, La ciudad dividida. El olvido en la memoria de Atenas, Buenos Aires, Katz Editores, 2008b.

Loraux, Nicole, La invención de Atenas: Historia de la oración fúnebre en la "ciudad clásica”, Buenos Aires, Katz Editores, 2012.

Low, Polly, "Looking for the Language of Athenian Imperialism", Journal of Hellenic Studies, 125, 2005, pp. 93-111.

Low, Polly, Interstate Relations in Classical Greece. Morality and Power, Cambridge, Cambridge University Press, 2007.

Moreno Leoni, Álvaro, Entre Roma y el Mundo Griego. Memoria, autorrepresentación y didáctica del poder en las Historias de Polibio, Córdoba, Editorial Brujas (Studia Ordia Prima, 8), 2017.

Morris, Ian, "The Greater Athenian State", in Ian Morris \& Walter Scheidel (eds.), The Dynamics of Ancient Empires. State Power from Assyria to Byzantium, Oxford, Oxford University Press, 2009, pp. 99-177. 
Mossé, Claude, “Citoyens actifs et citoyens 'passifs' dans les cités grecques: une approche théorique du problème", Revue des Études Anciennes, 81, 1979, pp. 241249, www.persee.fr/doc/rea_0035-2004_1979_num_81_3_4061 (23/04/2018).

Ober, Josiah, Political Dissent in Democratic Athens. Intellectual Critics of Popular Rule, New Jersey, Princeton University Press, 1998.

Olivera, Diego, “¿Krátos o Arkhé?: Consideraciones en torno al lenguaje bélico e imperial ateniense y sus repercusiones en el pensamiento político griego", Anacronismo e Irrupción, 5/9, 2015, pp. 11-29, https://publicaciones.sociales.uba. ar/index.php/anacronismo/article/view/1514 (10/12/2015).

OliverA, Diego, "Imperio y democracia en el pensamiento político griego", De rebus Antiquis, 8, 2018, pp. 17-43. http://erevistas.uca.edu.ar/index.php/DRA/ article/view/2524 (24/10/2019).

PAiAro, Diego, "Relaciones de dependencia en la Atenas clásica, entre la explotación y la dominación", Trabajos y Comunicaciones, 2a época, 38, 2012, pp. 153-184, http://www.trabajosycomunicaciones.fahce.unlp.edu.ar/article/view/ TyCn38a09/ (18/06/2019).

Payen, Pascal, Les îles nomades. Conquérir et résister dans l'Enquête d'Hérodote, Paris, Éditions de l'École des Hautes Études en Sciences Sociales, 1997.

PAYEN, Pascal, Les revers de la guerre en Grèce ancienne. Histoire et historiographie, Paris, Belin, 2012.

Pébarthe, Christophe, "L'empire athénien est-il toujours un empire comme les autres?", Dialogues d'histoire ancienne, Supplément 5, 2011, pp. 57-88, DOI: 10.3406/dha.2011.3494.

Pérez Martínez, José Alberto, “¿Imperio, imperialismo o hegemonía espartana? Una armonización conceptual para la Esparta del siglo v a.C.", Polis. Revista de ideas y formas políticas de la Antigüedad Clásica, 26, 2014, pp. 121-145, http://hdl.handle.net/10017/5291 (22/04/2018).

Plácido SuÁrez, Domingo, "De Heródoto a Tucídides", Gerión. Revista de Historia Antigua, 4, 1986, pp. 17-46.

Plácido SuÁrez, Domingo, La sociedad ateniense. La evolución social en Atenas durante la guerra del Peloponeso, Barcelona, Crítica, 1997.

RaAflaub, Kurt, "Democracy, Power, and Imperialism in Fifth-Century Athens", in J. Peter Euben, John R. Wallach \& Josiah Ober (comps.), Athenian Political Thought and the Reconstruction of American Democracy, Ithaca-London, Cornell University Press, 1994.

Rancière, Jacques, El desacuerdo. Política y filosofía, Buenos Aires, Nueva Visión, 1996.

SAmons II, Loren J., "Athens: A Democratic Empire”, in Kimberly Kagan (ed.), The Imperial Moment, Cambridge, Harvard University Press, 2010, pp. 12-31.

VAN WeEs, Hans, "La ciudad en guerra", en Robin Osborne (comp.), La Grecia Clásica, Barcelona, Crítica, 2002, pp. 95-127.

Van Wees, Hans, Greek Warfare. Myths and Realities, London, Duckworth, 2004.

Vernant, Jean-Pierre, Los orígenes del pensamiento griego, Buenos Aires, Paidós, 1992.

Vlassopoulos, Kostas, "Greek Slavery. From Domination to Property and Back Again”, Journal of Hellenics Studies, 131, 2011, pp. 115-130. 
WILL, Édouard, El mundo griego y el Oriente. Tomo I: El siglo v (510-403), Madrid, Akal, 1997.

Diego Alexander Olivera es doctor en Ciencias Sociales por la Universidad Nacional de Entre Ríos (Argentina), becario Posdoctoral del Consejo Nacional de Investigaciones Científicas y Técnicas (CONICET). Trabaja en el Instituto de Humanidades y Ciencias Sociales del Litoral de doble dependencia CONICET-Universidad Nacional del Litoral. Es profesor asistente en la Cátedra "Sociedades Grecolatinas" de la carrera de Historia de la Facultad de Humanidades, Artes y Ciencias Sociales de la Universidad Autónoma de Entre Ríos, fue profesor invitado en el Departamento de Ciencias de la Antigüedad y Edad Media de la Universidad Autónoma de Barcelona en 2017. Su principal línea de investigación es Historia del pensamiento político griego clásico y helenístico. Entre sus publicaciones recientes están los artículos "Imperio y democracia en el pensamiento político griego", De rebus Antiquis, 8, 2018, pp. 17-43, y “A Filopemén. Historia y Retórica en Polibio", Anales de Filología Clásica, 1, 30, 2017, pp. 33-42, así como el capítulo "Historia y comparativismo: Sir Moses Finley y el concepto de imperio en el mundo antiguo", en A. Moreno Leoni \& A. Moreno (comps.), Historiografía moderna y mundo antiguo, Córdoba, Tinta Libre, 2018. 